\title{
Structure-activity relationship study of novel iminothiadiazolo-pyrimidinone antimicrobial agents
}

\author{
Atmika Paudel $^{1}$, Keiichi Kaneko ${ }^{2}$, Ayako Watanabe ${ }^{1}$, Matsunaga Shigeki ${ }^{2,3}$, Kanai Motomu ${ }^{2}$, \\ Hiroshi Hamamoto ${ }^{1}$ and Kazuhisa Sekimizu ${ }^{1}$ \\ An iminothiadiazolo-pyrimidinone derivative, 0002-04-KK, harboring a furan moiety, acts as an antimicrobial agent with a \\ minimum inhibitory concentration (MIC) against Staphylococcus aureus of $25 \mu \mathrm{g} \mathrm{ml}^{-1}$. Several derivatives of 0002-04-KK were \\ synthesized and among them 0026-59-KK, harboring a nitrofuran moiety, had the most potent antimicrobial activity with an \\ MIC of $6 \mu \mathrm{g} \mathrm{ml}^{-1}$. Both 0002-04-KK and 0026-59-KK inhibited the biosynthesis of DNA, RNA and proteins. Peptidoglycan \\ biosynthesis was inhibited by 0026-59-KK, and slightly inhibited by 0002-04-KK. Derivative 0002-04-KK showed bactericidal \\ activity in contrast to the bacteriostatic activity of 0002-04-KK. Derivative 0002-04-KK had less toxicity in silkworms (lethal \\ dose fifty $\left.\left(\mathrm{LD}_{50}\right):>230 \mu \mathrm{gg}^{-1}\right)$ than $0002-04-\mathrm{KK}\left(\mathrm{LD}_{50}: 100 \mu \mathrm{gg}^{-1}\right)$. The bactericidal activity against $S$. aureus was \\ because of the nitrofuran moiety. These findings suggest that iminothiadiazolo-pyrimidinone compounds could be used as \\ lead molecules to develop antimicrobial agents.
}

The Journal of Antibiotics (2013) 66, 663-667; doi:10.1038/ja.2013.69; published online 3 July 2013

Keywords: bactericidal; macromolecule; nitrofuran; novel antimicrobial; structure-activity relationship

\section{INTRODUCTION}

The search for antimicrobial agents against human pathogens has been ongoing for centuries and remains a challenging task. Antimicrobials launched into the clinical field have led to the rapid emergence of more microbes resistant to these antimicrobials. The emergence of strains resistant to recently introduced antimicrobials enhances the threat of infectious diseases spreading around the globe. Many notorious resistant pathogens, such as methicillin-resistant Staphylococcus aureus, ${ }^{1,2}$ vancomycin-intermediate $S$. aureus, ${ }^{3,4}$ vancomycin-resistant Enterococcus faecalis, ${ }^{5}$ multidrug-resistant Pseudomonas aeruginosa, ${ }^{6}$ and multidrug-resistant Mycobacterium tuberculosis ${ }^{7}$ cause serious problems for health-care facilities as well as the community. Hence, the development of new antimicrobial agents continues to be an urgent issue. To combat resistant strains, new structural antimicrobial agents are required. Here we identified a novel antimicrobial agent and modified its structure to reduce toxicity and enhance antimicrobial activity.

\section{RESULTS}

Chemical library screening for antibacterial compounds against S. aureus

Among the 103873 compounds in the chemical library, we identified 3383 candidates $(3.3 \%)$ with antimicrobial activity against the S. aureus MSSA1 strain at a concentration of $100 \mu \mathrm{M}$. We selected 0002-04KK (1), whose antibacterial activity against $S$. aureus MSSA1 was
$25 \mu \mathrm{g} \mathrm{ml}^{-1}$. As the structure of the compound was promising, further studies of the structure function relationship were performed. First, we confirmed the antimicrobial activity by the synthesis of $\mathbf{1}$. Then, we evaluated the toxicity of 1 using silkworms. The median lethal dose $\left(\mathrm{LD}_{50}\right)$ value of the compound in the silkworm was $100 \mu \mathrm{g} \mathrm{g}^{-1}$.

\section{Structure-activity relationship of 1}

To enhance the antibacterial activity and reduce the toxicity of $\mathbf{1}$, we examined the structure-activity relationship (SAR). Toxicity was tested using silkworms as a model animal. ${ }^{8}$ Iminothaidiazolopyrimidinone (Table 1) was used as the mother compound and structures at the $R^{1}$ and $R^{2}$ positions were modified to obtain nine different compounds. Figure 1 summarizes the synthesis of derivatives of 1. Condensation of 2-amino-5-substituted-1,3,4-thiadiazole and ethyl cyanoacetate gave 5-imino-2-(substituted)- $5 \mathrm{H}$-(1,3,4)thiadiazolo(3,2-a)pyrimidin-7(6H)-one. Further reaction with aldehyde $\left(\mathrm{R}^{2} \mathrm{CHO}\right)$ in the presence of a catalytic amount of $\mathrm{Et}_{3} \mathrm{~N}$ gave products of $28-70 \%$ yield. Table 1 shows the results of the SAR analysis. Compound 0026-59-KK (2) exhibited the strongest antibacterial activity against $S$. aureus and had the least toxicity in silkworms. Hence, this compound was selected for further evaluation.

Antimicrobial spectrum of 1 and 2

Antimicrobial activities of 1 and 2 were tested with various microorganisms including Gram-positive bacteria, Gram-negative bacteria

${ }^{1}$ Laboratory of Microbiology, Graduate School of Pharmaceutical Sciences, The University of Tokyo, Tokyo, Japan; ${ }^{2}$ Graduate School of Pharmaceutical Sciences, The University of Tokyo, Tokyo, Japan and ${ }^{3}$ JST, ERATO, Kanai Life Science Catalysis Project, Hongo, Bunkyo-ku, Tokyo, Japan

Correspondence: Professor K Sekimizu, Laboratory of Microbiology, Graduate School of Pharmaceutical Sciences, The University of Tokyo, Tokyo 113-0033, Japan.

E-mail: sekimizu@mol.f.u-tokyo.ac.jp

Received 23 March 2013; revised 28 May 2013; accepted 30 May 2013; published online 3 July 2013 




Abbreviation: MIC, minimum inhibitory concentration.

and some fungi. Both compounds had antimicrobial activity against Gram-positive bacteria, including antibiotic-resistant strains such as methicillin-resistant $S$. aureus and vancomycin-resistant E. faecalis. Compound $\mathbf{2}$ showed more potent activity than 1 (Table 2). Neither compounds exerted any antimicrobial activity against Gram-negative bacteria. Compound $\mathbf{1}$ also had weak activity against some fungi, such as Candida and Cryptococcus, but not Aspergillus niger, whereas 2 exhibited no antifungal activity.
Mechanism of antibacterial action of 1 and 2

Pulse-labeling experiments for $30 \mathrm{~min}$ were performed. Both 1 and 2 inhibited the incorporation of radiolabeled precursors, $\left[{ }^{3} \mathrm{H}\right]$ thymidine, $\left[{ }^{3} \mathrm{H}\right]$ uridine and $\left[{ }^{35} \mathrm{~S}\right]$ methionine into acid-insoluble fractions in exponentially growing $S$. aureus (Figure 2). Incorporation of $\left[{ }^{3} \mathrm{H}\right] \mathrm{N}$-acetyl glucosamine was inhibited by 2 and slightly inhibited by 1 (Figure 2). Interestingly, 2 showed bactericidal activity, whereas $\mathbf{1}$ did not; 1 merely exhibited bacteriostatic activity (Figure 3). The bactericidal activity of 2 was potent: it killed $>99.9 \%$ of bacteria 
<smiles>[R]C1=NN2C(=N)CC(=O)N=C2S1</smiles>

$64 \%, \mathrm{R}=\mathrm{CF}_{3}:$ 0001-03-KK $97 \%, \mathrm{R}=\mathrm{Ph}: \mathbf{0 0 0 5}-\mathbf{0 8}-\mathrm{KK}$<smiles>[R]C(=O)[CH+]C(=O)CC(=N)n1nc([R16])sc1=NC</smiles><smiles>[R]C=C1C(=N)N2N=C([R7])SC2=NC1=O</smiles>

Figure 1 Scheme of synthesis of iminothiadiazolo-pyrimidinone derivatives.

Table 2 Minimum inhibitory concentration (MIC) of the compounds against microorganisms

\begin{tabular}{|c|c|c|}
\hline \multirow[b]{2}{*}{ Strain } & \multicolumn{2}{|c|}{ MIC $\left(\mu g m l^{-1}\right)$} \\
\hline & 1 & 2 \\
\hline S. aureus MSSA1 & 50 & 6.3 \\
\hline S. aureus RN4220 & 50 & 3.1 \\
\hline S. aureus NCTC8325-4 & 50 & 3.1 \\
\hline S. aureus Smith & 50 & 6.3 \\
\hline Methicillin-resistant S. aureus MRSA3 & 50 & 6.3 \\
\hline Methicillin-resistant $S$. aureus MRSA4 & 50 & 6.3 \\
\hline Methicillin-resistant $S$. aureus MRSA6 & 50 & 6.3 \\
\hline Methicillin-resistant $S$. aureus MRSA8 & 50 & 6.3 \\
\hline Methicillin-resistant S. aureus MRSA9 & 25 & 6.3 \\
\hline Methicillin-resistant S. aureus MRSA11 & 50 & 3.1 \\
\hline Methicillin-resistant S. aureus MRSA12 & 50 & 6.3 \\
\hline Enterococcus faecalis EF1 & 100 & 25 \\
\hline Vancomycin-resistant Enterococcus faecalis EF5 (VRE) & 100 & 12.5 \\
\hline Bacillus subtilis JCM2499 & 100 & 6.3 \\
\hline Bacillus cereus JCM20037 & 100 & 3.1 \\
\hline Streptococcus sanguinis JCM5708 & $>100$ & 25 \\
\hline S. pyogenes SS1-9 & $>100$ & 25 \\
\hline S. agalactiae JCM5671 & $>100$ & 12.5 \\
\hline S. pneumoniae JCSC6523 & 50 & 1.5 \\
\hline Serratia marcescens 98-130-37 & $>100$ & $>100$ \\
\hline Escherichia coli W3110 & $>100$ & $>100$ \\
\hline Pseudomonas aeruginosa PAO1 & $>100$ & $>100$ \\
\hline Candida albicans ATCC10231 & 100 & $>100$ \\
\hline C. tropicalis pK233 & 100 & $>100$ \\
\hline Cryptococcus neoformans H99 & 100 & $>100$ \\
\hline Aspergillus niger & $>100$ & $>100$ \\
\hline
\end{tabular}

within $30 \mathrm{~min}$. The killing activity was comparable to that of daptomycin. To gain more insight into which moiety was responsible for the killing action, two other compounds, 0006-09-KK (3) and 0027-56-KK (4) were selected and a killing assay was performed. Compound 4 exhibited bactericidal activity, whereas 3 showed bacteriostatic activity (Figure 3 ).

\section{DISCUSSION}

In this study, we found novel iminothaidiazolo-pyrimidinone antimicrobial agents screened by an in vitro antimicrobial test from a chemical library. We successfully produced compounds with more potent antimicrobial activity against Gram-positive bacteria and less toxicity in a silkworm model. We previously demonstrated that the
$\mathrm{LD}_{50}$ values of cytotoxic compounds in the silkworm model are similar to those in mammalian models. ${ }^{9}$ Thus, in mammalian models the toxicity of synthesized compounds such as $\mathbf{2}$ would likely be reduced compared to that of the original screened 1. Antimicrobial activity of the mother structure has not yet been reported.

SAR studies are necessary to develop antimicrobial agents for clinical purposes. Our preliminary SAR study suggested that 2 harboring a benzene ring and a nitrofuran moiety in the $\mathrm{R}^{1}$ and $\mathrm{R}^{2}$ positions, respectively, was the most effective against $S$. aureus and less toxic to silkworm larvae. Nitrofuran-containing compounds are reported to have cytotoxic and carcinogenic activities. ${ }^{10,11}$ Although $\mathbf{2}$ has less acute toxicity, its long-term toxicity and carcinogenicity are unknown. The presence of hydrogen (0005-08-KK) and a furan ring (0023-37-KK) led to a decreased antibacterial activity (Table 1). In other cases, antibacterial activity was not affected, whereas toxicity was higher in trifluoro-methane containing groups. Closer comparison of the structures revealed that the trifluoro-methane moiety was responsible for the toxicity, except in 0019-25-KK (Table 1). The combination of trifluoro-methane and methylfuran moieties might be responsible for abolishing the toxicity owing to the counter action of the methylfuran moiety. The toxicity of the trifluoro-methane moiety was also verified by the antifungal activity possessed by 2 . These findings further support the usefulness of the silkworm model for identifying a low toxic modification based on the SAR. In the conventional method, the cytotoxicity of synthesized compounds is tested using an in vitro cell culture system, but this method does not reflect the pharmacokinetics of the tested compounds. Thus, the toxicity of compounds between individual and cultured cells does not always correspond. Testing the toxicity of many synthesized compounds using mammals, however, is not only costly but is also associated with ethical problems. The silkworm model solves these problems and accelerates the development of novel antimicrobial agents.

We found that $\mathbf{1}$ was bacteriostatic, whereas $\mathbf{2}$, which is a chemically modified version of $\mathbf{1}$, had potent bactericidal activity that killed S. aureus within $30 \mathrm{~min}$. Inhibition of the incorporation of radiolabeled precursors into the macromolecules revealed that both 1 and 2 inhibited the biosynthesis of all the macromolecules: DNA, RNA and proteins. Although peptidoglycan synthesis was inhibited by 2 , it was only slightly inhibited by 1 . Therefore, the potency of peptidoglycan synthesis inhibition was enhanced. The fact that $\mathbf{3}$ was bacteriostatic, whereas 4 was bactericidal, revealed that the nitrofuran moiety was responsible for the bactericidal activity. In the present study, SAR analysis led to the modification of a weak antimicrobial agent to a compound with potent antimicrobial activity; bacteriostatic activity was further improved to bactericidal activity. Further derivatization based on these results is required.

\section{METHODS}

\section{Microbial strains and culture conditions}

Gram-positive bacteria, including some resistant strains, Gram-negative bacteria and some fungi were used as test pathogens (Table 3). Bacterial cultures were prepared in either Luria Bertani medium (tryptone $10 \mathrm{~g}^{-1}$, yeast extract $5 \mathrm{~g} \mathrm{l}^{-1}, \mathrm{NaCl} 10 \mathrm{~g} \mathrm{l}^{-1}, \mathrm{pH} 7.0$ ) or Muller-Hinton Broth (MHB; Difco, Franklin Lakes, NJ, USA). Cation-adjusted MHB was used for antimicrobial susceptibility tests. For streptococcus species, cation-adjusted MHB with 2.5\% lysed horse blood (Nippon Biotest Laboratories Inc, Tokyo, Japan), was used. Minimum inhibitory concentration (MIC) was determined as per the Clinical and Laboratory Standards Institute, ${ }^{12}$ and Roswell Park Memorial Institute medium (Sigma Aldrich, St Louis, MO, USA) was used for testing antifungal susceptibility. Antifungal susceptibility was determined as per the Clinical and Laboratory Standards Institute. ${ }^{9}$ 

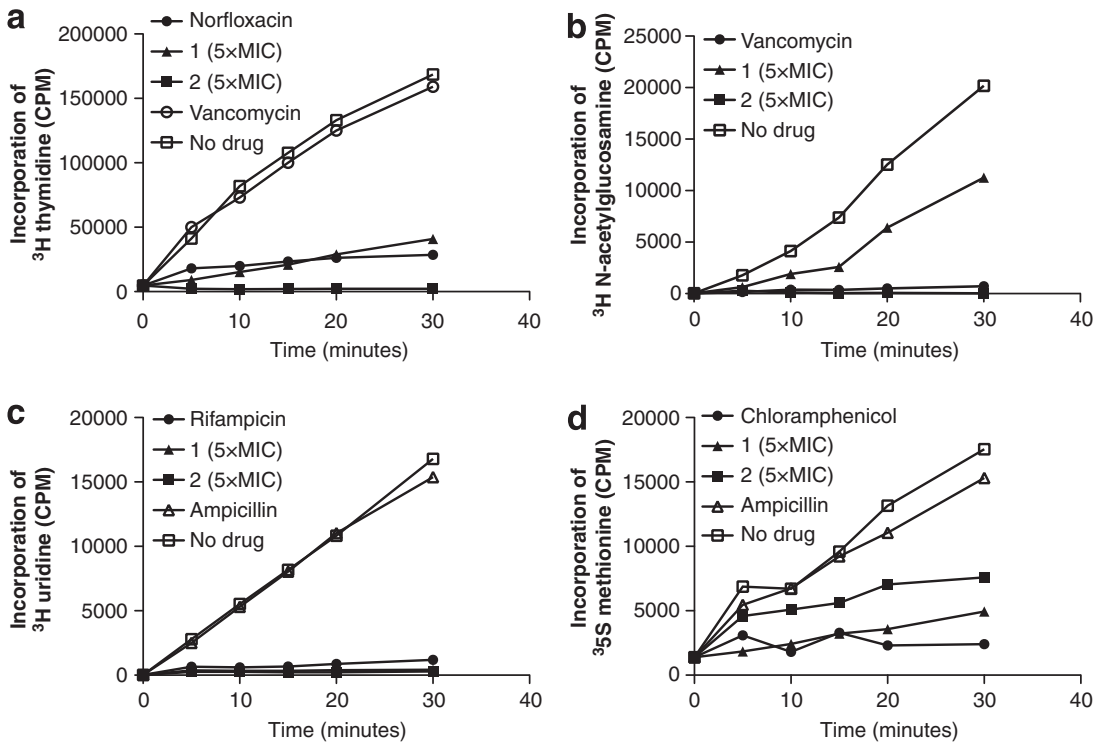

Figure 2 Effect of antimicrobial agents and comparator antibiotics on the incorporation of radiolabeled precursors in Staphylococcus aureus.



Figure 3 Effect of the compounds on Staphylococcus aureus viability.

\section{Chemicals and antibiotics}

All chemicals used were of analytical grade. Vancomycin, daptomycin and norfloxacin were purchased from Wako Pure Chemicals (Tokyo, Japan), Sequoia Research Products (Oxford, UK) and Sigma Aldrich, respectively. Rifampicin and chloramphenicol were obtained from Nacalai Tesque (Kyoto, Japan). Radiolabeled $\left[{ }^{3} \mathrm{H}\right] \mathrm{N}$-acetylglucosamine was obtained from American Radiolabeled Chemicals (St Louis, MO, USA), [methyl $\left.-{ }^{3} \mathrm{H}\right]$ thymidine and $\left[{ }^{3} \mathrm{H}\right]$ uridine were obtained from Moravek Biochemical (Brea, CA, USA) and $\left.{ }^{[35} \mathrm{S}\right]$ methionine was obtained from the Institute of Isotopes (Budapest, Hungary).

\section{Chemical library and screening method}

The chemical library of the Open Innovation Center for Drug Discovery at the University of Tokyo was screened for antibacterial activity against $S$. aureus MSSA1. Screening was based on MIC values against methicillin-susceptible $S$. aureus determined by broth dilution assay. Chemical compounds were screened with a criterion to obtain compounds with MIC values of $<100 \mu \mathrm{M}$.

\section{Synthesis of iminothiadiazolo-pyrimidinone derivatives}

Synthesis of 5-imino-2-(substituted)-5H-(1,3,4)thiadiazolo(3,2-a)pyrimidin$7(6 \mathrm{H})$-one $(0001-03-\mathrm{KK}$ and $0005-08-\mathrm{KK})$ :

Sodium $(140 \mathrm{mg})$ was dissolved into anhydrous ethanol $(20 \mathrm{ml})$, and 2-amino-5-substituted-1,3,4-thiadiazole $(5.9 \mathrm{mmol})$ and ethyl cyanoacetate $(5.9 \mathrm{mmol})$ were added to the solution. The resulting solution was refluxed for $8 \mathrm{~h}$, and then cooled to room temperature. The solution was poured onto
Table 3 Microbial strains used in this study

\begin{tabular}{|c|c|}
\hline Strain & Characteristics \\
\hline Staphylococcus aureus MSSA1 & MET-susceptible, clinical isolate \\
\hline S. aureus RN4220 & MET-susceptible \\
\hline S. aureus NCTC8325-4 & MET-susceptible \\
\hline S. aureus Smith & MET-susceptible \\
\hline S. aureus MRSA3 & $\begin{array}{l}\text { OFXA, KAN, TET, ERM-resistant, clinical } \\
\text { isolate }\end{array}$ \\
\hline S. aureus MRSA4 & $\begin{array}{l}\text { OFXA, KAN, CHL, CYP-resistant, clinical } \\
\text { isolate }\end{array}$ \\
\hline S. aureus MRSA6 & $\begin{array}{l}\text { OFXA, FLX, KAN, TET, CYP, IM/CS-resistant, } \\
\text { clinical isolate }\end{array}$ \\
\hline S. aureus MRSA8 & $\begin{array}{l}\text { OFXA, FLX, KAN, ERM, CYP, IM/CS-resistant, } \\
\text { clinical isolate }\end{array}$ \\
\hline S. aureus MRSA9 & $\begin{array}{l}\text { OFXA, FLX, TET, ERM, CYP, IM/CS-resistant, } \\
\text { clinical isolate }\end{array}$ \\
\hline S. aureus MRSA11 & $\begin{array}{l}\text { OFXA, KAN, ERM, CYP, IM/CS-resistant, } \\
\text { clinical isolate }\end{array}$ \\
\hline S. aureus MRSA12 & $\begin{array}{l}\text { OFXA, FLX, KAN, ERM, IM/CS-resistant, } \\
\text { clinical isolate }\end{array}$ \\
\hline Enterococcus feacalis EF1 & VM-susceptible \\
\hline E. feacalis EF5 & VM-resistant \\
\hline \multicolumn{2}{|l|}{ Streptococcus sanguinis JCM 5708} \\
\hline \multicolumn{2}{|l|}{ S. pyogenes SS1-9 } \\
\hline \multicolumn{2}{|l|}{ S. pneumoniae JCSC6523 } \\
\hline \multicolumn{2}{|l|}{ S. agalactiae JCM5671 } \\
\hline \multicolumn{2}{|l|}{ Bacillus subtilis JCM2499 } \\
\hline \multicolumn{2}{|l|}{ Bacillus cereus JCM20037 } \\
\hline \multicolumn{2}{|l|}{ Pseudomonas aeruginosa PAO1 } \\
\hline \multicolumn{2}{|l|}{ Escherichia coli W3110 } \\
\hline \multicolumn{2}{|l|}{ Serratia marcescens 98-130-37 } \\
\hline \multicolumn{2}{|l|}{ Candida albicans ATCC10231 } \\
\hline \multicolumn{2}{|l|}{ C. tropicalis pK233 } \\
\hline \multicolumn{2}{|l|}{ Cryptococcus neoformans H99 } \\
\hline Aspergillus niger & \\
\hline
\end{tabular}

Abbreviations: CHL, chloramphenicol; CYP, cyprofloxacin; ERM, erythromycin; FLX, flomoxef; IM/CS, imipenem/cilastatin sodium; KAN, kanamycin; MET, methicillin; OFXA, ofloxacin; TET, tetracycline; VM, vancomycin. 
ice water and acidified with acetic acid. The precipitate was collected and washed with water to afford $0001-03-\mathrm{KK}$ in $64 \%$ yield as a yellow solid and $0005-08-\mathrm{KK}$ in $97 \%$ yield as a colorless solid.

Synthesis of compounds 0002-04-KK, 0019-25-KK, 0021-27-KK, 0027-56KK, 0006-09-KK, 0017-22-KK, 0023-37-KK and 0026-59-KK:

Aldehyde $(0.86 \mathrm{mmol})$ and one drop of $\mathrm{Et}_{3} \mathrm{~N}$ were added to a solution of thiadiazolopyrimidine $0001-03-\mathrm{KK}$ or $0005-08-\mathrm{KK}(0.82 \mathrm{mmol})$ in dimethylformamide $(0.82 \mathrm{ml})$ and ethanol $(0.82 \mathrm{ml})$. The reaction mixture was heated at $50-60{ }^{\circ} \mathrm{C}$ for $3 \mathrm{~h}$ and then kept standing at $25^{\circ} \mathrm{C}$ for $12 \mathrm{~h}$ to obtain a precipitate. The resulting precipitate was collected by filtration and washed with dry diethyl ether to give products (0002-04-KK (1), 0019-25-KK, 002127-KK, 0027-56-KK (4), 0006-09-KK (3), 0017-22-KK, 0023-37-KK and 0026$59-$ KK (2)) of $28-70 \%$ yield. The physicochemical properties and structure elucidation details for the compounds are shown in the Supplementary Information

\section{Incorporation of $\left[{ }^{3} \mathrm{H}\right] \mathrm{N}$-acetylglucosamine into cell wall peptidoglycans}

Measurement of incorporated $\left[{ }^{3} \mathrm{H}\right] \mathrm{N}$-acetylglucosamine was performed as previously described by Paudel et al. ${ }^{12}$ Briefly, S. aureus NCTC8325-4 was cultured at $37^{\circ} \mathrm{C}$ overnight in CGPY broth $\left(\mathrm{Na}_{2} \mathrm{HPO}_{4}, 6 \mathrm{~g} ; \mathrm{NaCl}, 3 \mathrm{~g}\right.$; $\mathrm{MgCl}_{2} .6 \mathrm{H}_{2} \mathrm{O}, 0.1 \mathrm{~g} ; \mathrm{NH}_{4} \mathrm{Cl}, 2 \mathrm{~g} ; \mathrm{Na}_{2} \mathrm{SO}_{4}, 0.15 \mathrm{~g} ; \mathrm{KH}_{2} \mathrm{PO}_{4}, 3 \mathrm{~g}$; bactopeptone, $10 \mathrm{~g}$; yeast extract, $0.1 \mathrm{~g}$ and glucose, $5 \mathrm{gl}^{-1}, \mathrm{pH}$ 7.0). The culture was diluted 100 -fold with the same medium and further cultured until an optical density $(\mathrm{OD})_{660}$ of 0.2 was reached. The culture was centrifuged at $8000 \mathrm{~g}$ for $10 \mathrm{~min}$ and the pellet was suspended in modified cell wall synthesis medium $\left(\mathrm{KH}_{2} \mathrm{PO}_{4}, 6 \mathrm{~g} ; \mathrm{K}_{2} \mathrm{HPO}_{4}, 6 \mathrm{~g} ; \mathrm{NH}_{4} \mathrm{Cl}, 2 \mathrm{~g} ; \mathrm{MgSO}_{4} .7 \mathrm{H}_{2} \mathrm{O}, 5 \mathrm{mg} ; \mathrm{FeSO}_{4}, 5 \mathrm{mg} ;\right.$ glucose, $100 \mathrm{mg}$; uracil, $40 \mathrm{mg}$; L-alanine, $50 \mathrm{mg}$; L-glutamic acid, $120 \mathrm{mg}$; L-lysine, $50 \mathrm{mg}$ and chloramphenicol, $100 \mathrm{mgl}^{-1}$ ), $\mathrm{pH}$ 6.8) to obtain $\mathrm{OD}_{660}=0.1$. In the presence of $35 \mu \mathrm{Ci}\left[{ }^{3} \mathrm{H}\right] \mathrm{N}$-acetyl glucosamine, 1, 2, vancomycin, or norfloxacin $(5 \times \mathrm{MIC})$ was added to $1 \mathrm{ml}$ of the cell suspension at time zero and incubated at $37^{\circ} \mathrm{C}$ with shaking at 150 r.p.m. Samples were collected at the indicated times and an equal volume of $10 \%$ trichloroacetic acid was added. The mixture was incubated at $90{ }^{\circ} \mathrm{C}$ for $15 \mathrm{~min}$, placed on ice for $30 \mathrm{~min}$ and filtered with a membrane filter $(0.45 \mu \mathrm{m} \mathrm{HA}$, Millipore, County Cork, Ireland) followed by washing with 5\% trichloroacetic acid. Radioactivity was counted on a liquid scintillation counter (LS6000SE, Beckman Coulter, Brea, CA, USA) and expressed as c.p.m.

\section{Incorporation of radiolabeled thymidine, uridine and methionine} Incorporation of thymidine, uridine, and methionine was measured as described previously. ${ }^{10}$ Briefly, S. aureus NCTC8325-4 was grown overnight in Luria Bertani medium at $37^{\circ} \mathrm{C}$. The culture was diluted 200 -fold in Luria Bertani medium and incubated at $37^{\circ} \mathrm{C}$ until an $\mathrm{OD}_{600}$ of 0.3 was reached. Either $7 \mu \mathrm{Ci}\left[{ }^{3} \mathrm{H}\right]$ uridine, $70 \mu \mathrm{Ci}\left[{ }^{3} \mathrm{H}\right]$ thymidine or $20 \mu \mathrm{Ci}\left[{ }^{35} \mathrm{~S}\right]$ methionine was added to the culture. Rifampicin, norfloxacin and chloramphenicol at a concentration of $5 \times$ MIC were used to inhibit RNA, DNA and protein synthesis, respectively; and vancomycin or ampicillin $(5 \times$ MIC) was used as a negative control. Compounds $\mathbf{1}$ and $2(5 \times$ MIC) were used for all the assays. The MICs of rifampicin, norfloxacin, chloramphenicol, vancomycin and ampicillin were $0.004 \mu \mathrm{g} \mathrm{ml}^{-1}, 0.5 \mu \mathrm{g} \mathrm{ml}^{-1}, 4 \mu \mathrm{g} \mathrm{ml}^{-1}, 1 \mu \mathrm{g} \mathrm{ml}^{-1}$ and $0.03 \mu \mathrm{g} \mathrm{ml}^{-1}$, respectively. At time zero, agents were added to exponentially growing cultures. Aliquots were collected at the indicated times, diluted twice with $5 \%$ trichloroacetic acid and the acid-insoluble fraction was obtained by filtration through glass fiber filters (Whatman, GE Healthcare, Maidstone, Kent, UK). Radioactivity retained on the filters was measured on a liquid scintillation counter and expressed as c.p.m.

\section{Killing assay}

The killing assay was performed as per the National Committee for Clinical Laboratory Standards. ${ }^{11}$ Briefly, an overnight culture of S. aureus MSSA1 at $37^{\circ} \mathrm{C}$ in MHB was diluted 1000 times with MHB medium and cultured for $2 \mathrm{~h}$ at $37^{\circ} \mathrm{C}$. For daptomycin, MHB was supplemented with $50 \mathrm{mgl}^{-1} \mathrm{Ca}^{2+}$. Compounds 1, $2\left(5 \times\right.$ MIC), or daptomycin $\left(5 \times\right.$ MIC; MIC: $\left.1 \mu \mathrm{g} \mathrm{ml}^{-1}\right)$ was added to $1 \mathrm{ml}$ of the culture and incubated at $37^{\circ} \mathrm{C}$ for $0-24 \mathrm{~h}$. Culture aliquots were collected at the indicated times, diluted and spread on Luria Bertani agar plates and incubated at $37^{\circ} \mathrm{C}$ for $24 \mathrm{~h}$. Cell viability was determined by the colony-forming units per $\mathrm{ml}$. The lower limit of detection was $10^{4}$ colony-forming units per $\mathrm{ml}$.

\section{Toxicity tests in silkworms}

Fifth instar silkworm larvae were injected into the hemolymph with $0-400 \mu \mathrm{g}$ of each compound and observed for 3 days. The $\mathrm{LD}_{50}$ was determined as the amount of chemical $\left(\mu \mathrm{gg}^{-1}\right)$ that killed $50 \%$ of the larvae.

\section{CONFLICT OF INTEREST}

The authors declare no conflict of interest.

\section{ACKNOWLEDGEMENTS}

We thank the Chemical Library in the Open Innovation Center for Drug Discovery at the University of Tokyo for providing the compounds used in this study. We also thank Ms Matsuzawa, Ms Noguchi (Yoshino) and Ms Kyougoku for technical assistance. This study was supported by the Program for Promotion of Fundamental Studies in Health Sciences of the National Institute of Biomedical Innovation (NIBIO) and partly supported by JSPS Grant-in-Aid for Young Scientists (A) (24689008) from JSPS (HH) and Grant-in-Aid for Scientific Research on Innovative Areas (24102510) from MEXT (KS), and Platform for Drug Discovery, Informatics (MS).

1 Jevons, M. P. "Celbemom"-resistant staphylococci. Br. Med. J. 1, 113-114 (1961).

2 Chambers, H. F. \& Deleo, F. R. Waves of resistance: Staphylococcus aureus in the antibiotic era. Nat. Rev. Microbiol. 7, 629-641 (2009).

3 Hiramatsu, K. et al. Methicillin-resistant Staphylococcus aureus clinical strain with reduced vancomycin susceptibility. J. Antimicrob. Chemother. 40, 135-136 (1997).

4 Howden, BP, Davies, JK, Johnson, PD, Stinear, TP \& Grayson, ML. Reduced vancomycin susceptibility in Staphylococcus aureus, including vancomycin-intermediate and heterogeneous vancomycin-intermediate strains: resistance mechanisms, laboratory detection, and clinical implications. Clin. Microbiol. Rev. 23, 99-139 (2010).

5 Leclercq, R, Derlot, E, Duval, J \& Courvalin, P. Plasmid-mediated resistance to vancomycin and teicoplanin in Enterococcus faecium. N. Engl. J. Med. 319, 157-161 (1988).

6 Giske, CG, Monnet, DL, Cars, O \& Carmeli, Y. Clinical and economic impact of common multidrug-resistant gram-negative bacilli. Antimicrob. Agents. Chemother. 52, 813-821 (2008).

7 Migliori, GB et al. MDR-TB and XDR-TB: drug resistance and treatment outcomes Eur. Resp. J. 34, 778-779 (2009).

8 Hamamoto, H, Tonoike, A, Narushima, K, Horie, R \& Sekimizu, K. Silkworm as a model animal to evaluate drug candidate toxicity and metabolism. Comp. Biochem. Physiol. C. Toxicol. Pharmacol. 149, 334-339 (2009).

9 Clinical and Laboratory Standards Institute. Reference method for Broth Dilution Antifungal Susceptibility Testing of Yeasts: Approved Standard M27-A (Clinical and Laboratory Standards Institute, Wayne, PA, USA, 1997).

10 Paudel, A et al. Identification of novel deoxyribofuranosyl indole antimicrobial agents. J. Antibiot. (Tokyo) 65, 53-57 (2012).

11 National Committee for Clinical Laboratory Standards. Methods for Determining Bactericidal Activity of Antimicrobial Agents; Approved Guideline NCCLS Document M26-A, Vol. 19. (National Committee for Clinical Laboratory Standards, Wayne, PA, USA, 1999).

12 Clinical and Laboratory Standards Institute. Methods for Dilution Antimicrobial Susceptibility Tests for Bacteria that Grow Aerobically; Approved Standard, CLSI document M07-A8, 8th edn, Vol. 29 (Clinical and Laboratory Standards Institute, Wayne, PA, USA, 2009). 